Занковский С.С.

Заслуженный юрист РФ, доктор юридических наук, профессор, главный научный сотрудник Института государства и права РАН.

\title{
О ЗЛОУПОТРЕБЛЕНИИ ПРАВОМ ПО ГРАЖДАНСКОМУ ЗАКОНОДАТЕЛЬСТВУ
}

B статье рассмотрено такое последствие злоупотребления Анавомация недействительность сделки, а также вопросы применения правил о злоупотреблении правом к отношениям между основным и дочерним акционерными обществами и в русле практики договорного права.

Ключевые слова: гражданское законодательство, судебная практика, собственность, юридические лица, акционерное общество, недействительная сделка, кредитор, сторона.

Keywords: civil law, jurisprudence, property, legal entities, joint-stock company, invalid transaction, creditor, party.

Интерес в доктрине и практике к такому явлению, как злоупотребление правом, объясняется его универсальным характером как средства «нападения» или защиты. Действительно, в условиях, когда нарушения, допущенные контрагентом, не позволяют однозначно их квалифицировать, потерпевшая стороны в целях защиты своих интересов обращается к правилам ст. 10 ГК уже потому, что их применение во многом носит оценочный характер. Не менее важен и вопрос сочетания оговоренных в указанной статье мер с другими способами защиты прав.

В соответствии с ч. 3 ст. 17 Конституции РФ осуществление прав и свобод человека и гражданина не должно нарушать права и свободы других лиц. Данное конституционное требование реализовано в ряде норм гражданского законодательства, направленных против злоупотребления правом участниками гражданского оборота (см. Определение Конституционного Суда РФ от 20.12.2001 № 292-О) [1].

Одной из таких норм служит п. 1 ст. 10 ГК РФ, в котором содержится запрет на осуществление гражданских прав исключительно с намерением причинить вред другому лицу, действия в обход закона с противоправной целью, а также иное заведомо недобросовестное осуществление гражданских прав, т.е. злоупотребление правом.

Указанные действия квалифицируются в доктрине гражданского права как разновидность гражданского правонарушения, суть которого состоит в осуществлении лицом принадлежащего ему права с неправомерной целью причинить вред другому лицу, с превышением его пределов или в недопустимых формах.

При этом в том случае, когда личные права осуществляются в противоречии с их назначением, т.е., пользуясь словами С.Н. Братуся, вопреки их социальной ценности, судом может быть отказано в защите нарушенного права (на основании ст. 10 ГК РФ или другой специальной нормы закона) [2].

В русле последствий недобросовестного поведения, предусмотренных ст. 10 ГК РФ, лежит результат применения принципа "эстоппель" - отказ лицу в защите принадлежащего ему права полностью или частично[3].

Таким образом, основная санкция в отношении лица, допустившего злоупотребление правом, предусмотрена в п. 2 ст. 10 ГК РФ и состоит в том, что суд может отказать такому лицу в защите принадлежащего ему права. Из этого положения исходит сложившаяся к настоящему времени практика арбитражных судов, которые отказывают в удовлетворении исковых требований стороны обязательства, в действиях которой усматриваются признаки злоупотребления правом (см., например, постановление Президиума Высшего Арбитражного Суда РФ от 21.08.2001 № 1194/99; п. 38 постановления Пленума Высшего Арбитражного Суда РФ от 06.10.2005 № 30 «О некоторых вопросах практики применения Федерального закона «Устав железнодорожного транспорта Российской Федерации»; п. 30 приложения к информационному письму Президиума Высшего Арбитражного Суда РФ от 22.12.2005 № 96 
«Обзор практики рассмотрения арбитражными судами дел о признании и приведении в исполнение решений иностранных судов, об оспаривании решений третейских судов и о выдаче исполнительных листов на принудительное исполнение решений третейских судов» и др.)[4].

Что касается стороны обязательства или иных лиц, в отношении которых допущено злоупотребление правом, то в силу п. 1 ст. 4 АПК РФ такие лица вправе обратиться в арбитражный суд, если считают, что в результате допущенного злоупотребления имело место нарушение их прав и законных интересов. При этом следует иметь в виду, что ГК РФ в соответствии с вытекающими из Конституции РФ основными началами гражданского законодательства не ограничивает лицо в выборе способов защиты нарушенного права; в силу ст. 9 ГК РФ граждане и юридические лица вправе осуществить этот выбор по своему усмотрению (см. п. 3 постановления Конституционного Суда РФ от 21.04.2003 № 6-П) [1]. Отказ от права на обращение в суд недействителен.

Правило, установленное в ст. 168 ГК РФ, развивает положения ч. 2 ст. 15 Конституции РФ об обязанности граждан и их объединений соблюдать Конституцию РФ, законы и является одним из допустимых способов защиты прав заинтересованных лиц.

Как уже отмечалось, в п. 1 ст. 10 ГК РФ установлено правило, в силу которого не допускается осуществление гражданских прав исключительно с намерением причинить вред другому лицу, действия в обход закона с противоправной целью, а также иное заведомо недобросовестное осуществление гражданских прав, т.е. злоупотребление правом. Использование законодателем формулировки «не допускается» означает, что злоупотребление правом не соответствует закону. Иное толкование в данном случае неприемлемо, так как оно означало бы признание действий, которые законодатель считает при любых обстоятельствах недопустимыми, соответствующими закону.

Следовательно, поскольку действия лиц (в том числе в виде сделок), осуществляемые с намерением причинить вред другому лицу, не соответствуют требованиям закона (п. 1 ст. 10 ГК РФ), лицо, считающее, что допущенным злоупотреблением нарушены его права и охраняемые законом интересы, вправе прибегнуть к такому способу защиты этих прав и интересов, как обращение в суд с требованием о признании сделки недействительной на основании ст. 168 ГК РФ.

Ограничение законодательных санкций за умышленные действия, направленные на причинение вреда, отказом в судебной защите притязаний лица, допустившего данные действия, противоречило бы, в частности, приведенной позиции Конституционного Суда РФ и, кроме того, нарушило бы общеправовые принципы справедливости и соразмерности санкций характеру правонарушения.

На этих позициях прочно стоит судебная практика. Так, злоупотребление со стороны страховщика при заключении договора имущественного страхования может, как указал Верховный Суд РФ, повлечь признание такого договора недействительным [5].

Сделан также вывод о том, что злоупотребление правом при совершении сделки нарушает запрет, установленный ст. 10 ГК РФ, поэтому такая сделка признается недействительной на основании ст. 10 и 168 ГК РФ[5].

При осуществлении стороной права на одностороннее изменение условий обязательства или односторонний отказ от его исполнения она должна действовать разумно и добросовестно, учитывая права и законные интересы другой стороны (пункт 3 статьи 307, пункт 4 статьи 450.1 ГК РФ). Нарушение этой обязанности может повлечь отказ в судебной защите названного права полностью или частично, в том числе признание ничтожным одностороннего изменения условий обязательства или одностороннего отказа от его исполнения (пункт 2 статьи 10, пункт 2 статьи 168 ГК РФ)[6].

В то же время, поскольку согласно пункту 4 статьи 1 ГК РФ никто не вправе извлекать преимущество из своего недобросовестного поведения, слабая сторона договора вправе заявить о недопустимости применения несправедливых договорных условий на основании статьи 10 ГК РФ или о ничтожности таких условий по статье 169 ГК РФ[7] 
И если совершение сделки нарушает запрет, установленный пунктом 1 статьи 10 ГК РФ, в зависимости от обстоятельств дела такая сделка может быть признана судом недействительной (пункты 1 или 2 статьи 168 ГК РФ)[7].

Таким образом, действующее законодательство и судебная практика не ограничивают способы защиты интересов лица, в отношении которого допущено злоупотребление правом, только отказом в судебной защите возникших в результате злоупотребления прав. Сделка, направленная на причинение вреда другому лицу, может быть признана недействительной (ничтожной) в силу ст. 10 и ст. 168 ГК РФ в судебном порядке.

Исходя из изложенных выше соображений, подпадает под действие ст. 168 ГК РФ сделка, совершенная дочерним обществом во исполнение обязательных для него указаний основного общества и направленная на причинение вреда другой стороне такой сделки, дочернему обществу или третьим лицам.

Этот вывод не может быть поставлен под сомнение в связи с тем, что дочернее общество вступает в указанную сделку во исполнение обязательных указаний основного общества, т.к. факт выполнения таких указаний не предусмотрен в законодательстве в качестве признака, исключающего возможность квалификации сделки как не соответствующей требованиям закона в силу ст. 168 ГК РФ.

При этом недействительная сделка, как указано в п. 1 ст. 167 ГК РФ, не влечет правовых последствий, кроме тех, которые связаны с ее недействительностью, и недействительна с момента ее совершения. В связи с этим необходимо учесть, что ответственность, в т. ч. солидарная, может являться последствием нарушения стороной обязательства, возникшего из сделки. Поскольку недействительная сделка обязательство не порождает, ответственность сторон по такой сделке возникнуть не может.

В то же время по смыслу ст. 6 Федерального закона от 26.12.1995 N 208-Ф3 (ред. от 31.07.2020, с изм. от 24.02.2021)"Об акционерных обществах" основное общество должно отвечать солидарно с дочерним обществом применительно к недействительным сделкам дочернего общества, заключенным последним во исполнение обязательных указаний, за все последствия, связанные с недействительностью такой сделки.

Таким образом, приведенное правило не ограничивает средства правовой защиты в связи со сделкой, заключенной дочерним обществом во исполнение обязательных для него указаний основного общества, направленной на причинение вреда дочернему обществу и/или третьим лицам, только теми средствами, которые связаны с солидарной ответственностью основного и дочернего обществ применительно к такой сделке. Сделка, заключенная дочерним обществом во исполнение обязательных для него указаний основного общества, направленная на причинение вреда дочернему обществу и/или третьим лицам, может быть признана недействительной (ничтожной) в силу ст. 10 и ст. 168 ГК РФ в судебном порядке. Основное общество отвечает солидарно с дочерним обществом за все последствия, связанные с недействительностью сделки, заключенной дочерним обществом во исполнение обязательных указаний основного общества.

Анализ содержания ст. 6 Закона об акционерных обществах позволяет придти к выводу о том, что в нем предусмотрены три группы правовых оснований для признания хозяйственного общества дочерним. К первой из них относится преобладающее участие основного общества в уставном капитале дочернего; ко второй - заключенный между ними договор, и к третьей - все иные основания, не противоречащие законодательству.

Признание общества дочерним по приведенным факторам дает возможность основному обществу определять принимаемые дочерним обществом решения, причем в случаях, когда такие решения имеют форму обязательных указаний, основное и дочернее общества несут солидарную ответственность по сделкам, заключенным дочерним обществом во исполнение этих указаний.

Отсюда видно, что ст. 6 указанного Закона не содержит исчерпывающего перечня ситуаций, обусловливающих право основного общества давать дочернему обязательные указания и его обязанность нести совместно с последним солидарную ответственность. Такой подход представляется оправданным по той причине, что взаимоотношения основного и дочернего обществ на практике слишком многообразны для того, чтобы сформулировать в 
законе закрытый перечень. Кроме того, формулировка подобного рода могла бы привести к тому, что обязанность дочернего общества по исполнению указаний основного общества, лежащая вне перечня, не сопровождалась бы его солидарной ответственностью по сделкам, что недопустимо.

Аналогичная позиция содержится в п. 31 совместного постановления пленумов Верховного Суда РФ и Высшего Арбитражного Суда РФ от 01.07.1996 № 6/8 «О некоторых вопросах, связанных с применением части первой Гражданского кодекса Российской Федерации»[4], где применительно к вопросу солидарной ответственности основного и дочернего обществ указывается на необходимость иметь в виду, что взаимоотношения двух хозяйственных обществ могут рассматриваться как взаимоотношения основного и дочернего общества, в т. ч. и применительно к отдельной конкретной сделке, в случаях, когда основное общество имеет возможность определять решения, принимаемые дочерним обществом, либо давать обязательные для него указания.

Исходя из этого, следует констатировать, что содержащееся в п. 3 ст. 6 Закона об акционерные общества правило о том, что основное общество считается имеющим право давать дочернему обществу обязательные для последнего указания только в случае, когда это право предусмотрено в договоре с дочерним обществом или его уставе, не вводит исчерпывающий перечень факторов, определяющих случаи, когда дочернее общество признается действующим во исполнение обязательных указаний основного общества. Этой статьей установлены только случаи, когда наличие права давать дочернему обществу обязательные указания презюмируется (наличие такого права презюмируется, если оно предусмотрено в договоре с дочерним обществом или уставе дочернего общества). Об этом свидетельствует использование в тексте п. 3 ст. 6 Федерального закона от 26.12.1995 № 208Ф3 «Об акционерных обществах» слова «считается», что указывает на обозначенную презумпцию, но не исключает возможность наличия иных обстоятельств, в которых дочернее общество должно быть признано действующим во исполнение обязательных указаний основного общества.

Кроме того, следует принять во внимание, что если бы содержащееся в п. 3 ст. 6 Закона об акционерных общества правило о том, что основное общество считается имеющим право давать дочернему обществу обязательные для последнего указания только в случае, когда это право предусмотрено в договоре с дочерним обществом или его уставе, вводило исчерпывающий перечень факторов, определяющих солидарную ответственность основного и дочернего обществ, то это правило вступило бы в противоречие с самой практикой взаимоотношений между указанными субъектами.

Таким образом, перечень оснований, указанных в абз. 3 п. 3 ст. 6 Федерального закона «Об акционерных обществах», не является исчерпывающим для признания того, что дочернее общество действует во исполнение обязательных указаний основного общества. В каждом конкретном случае могут быть установлены иные не противоречащие закону основания для признания дочернего общества действующим во исполнение обязательных указаний основного общества, что, в свою очередь, влечет возникновение у основного общества солидарной ответственности наряду с дочерним за действия, совершенные во исполнение таких обязательных указаний.

Обращаясь, далее, к договорному праву, рассмотрим необычный спор, возникший между ООО "Парижский бал" (в дальнейшем - ООО) и ПАО "Восток" (в дальнейшем ПАО).

Между сторонами возникла в силу договора следующая схема взаимодействия: ООО брало на себя организацию культурного мероприятия, а ПАО приобретало у ООО билеты на него для последующей их продажи всем желающим посетить такое мероприятие. Интерес к сделке со стороны ООО состоял не только в получении денежных сумм за билеты, но и в оказании посетителям мероприятия платных услуг, а ПАО получало свою выгоду от перепродажи билетов.

Однако в 2020 г. в результате пандемии ПАО не удалось реализовать большую часть купленных им у ООО билетов. В связи с этим ООО предъявило требование о возмещении ПАО причиненных ООО убытков в результате несостоявшегося мероприятия. 
Защищаясь от иска, ПАО полагало, что со стороны ООО имело место злоупотребление правом.

Однако на самом деле стороны заключили смешанный договор: купли-продажи билетов и возмездного оказания услуг по их распространению.

Но поскольку билеты перешли в собственность ПАО в силу п. 1 ст. 454 ГК РФ, условия договора, в которых предусмотрена обязанность ПАО по распространению билетов, лишены правового значения, т.к. собственнику принадлежит право распоряжения его имуществом (п. 1 ст. 209 ГК РФ) и, приобретая такое имущество по договору, собственник не может быть обязан тем же договором перепродать его третьим лицам.

В п. 47 постановления Пленума Верховного Суда РФ от 25.12.2018 N 49 указано, что при квалификации договора для решения вопроса о применении к нему правил об отдельных видах договоров (п. п. 2 и 3 ст. 421 ГК РФ) следует учитывать прежде всего существо законодательного регулирования соответствующего вида обязательств и признаки договоров, предусмотренных законом или иным правовым актом.

Равным образом, в постановлении Президиума ВАС РФ от 12.07.2011 N 17389/10 по делу N A28-732/2010-31/18 говорится о том, что свобода договора не означает, что при заключении договора стороны могут действовать и осуществлять права по своему усмотрению без учета прав других лиц (контрагентов), а также ограничений, установленных Гражданским кодексом РФ и другими законами.

Иными словами, обязательства купли-продажи и услуг в данном случае ввиду принципиального различия между их содержанием не могли составить смешанный договор. В силу ст. 1 ГК РФ граждане (физические лица) и юридические лица приобретают и осуществляют свои гражданские права своей волей и в своем интересе. В связи с этим и с учетом правомочия собственника по распоряжению принадлежащим ему имуществом, условие договора, ограничивающее такое правомочие, нельзя признать правомерным.

Кроме того, специфика данного спора заставляет обратиться к позиции Верховного Суда РФ в отношении правовых последствий непреодолимой силы. Наступление подобных обстоятельств, как разъяснил Верховный Суд, само по себе не прекращает обязательство должника, если исполнение остается возможным после того, как они отпали. Сторона освобождается от возмещения убытков или уплаты другой стороне неустойки и иных санкций, вызванных просрочкой исполнения обязательства ввиду непреодолимой силы (статьи 401, 405, 406, 417 ГК РФ).

В то же время договор может предусматривать специальные правила о прекращении обязательств на случай возникновения обстоятельств непреодолимой силы, например об автоматическом прекращении договорных отношений при наличии указанных обстоятельств либо о прекращении договорных отношений по истечении определенного срока с момента возникновения указанных обстоятельств (статья 421 ГК РФ)[8].

Иными словами, должник не отвечает перед кредитором за убытки, причиненные просрочкой исполнения обязательств вследствие наступления обстоятельств непреодолимой силы (пункт 3 статьи 401, пункт 2 статьи 405 ГК РФ)[9].

* Работа выполнена при информационной поддержке СПС «КонсультантПлюс».

\section{Литература}

1. Определение Конституционного Суда РФ от 20.12.2001 N 292-О "Об отказе в принятии к рассмотрению ходатайства граждан Бухтиярова Александра Ивановича, Бухтиярова Ивана Дмитриевича и Бухтияровой Стеллы Ивановны о разъяснении определения

Конституционного Суда Российской Федерации от 14 марта 2001 года об отказе в принятии к рассмотрению жалобы граждан Бухтиярова Александра Ивановича, Бухтиярова Ивана Дмитриевича и Бухтияровой Стеллы Ивановны на нарушение их конституционных прав статьей 333 Гражданского кодекса Российской Федерации".

2. Ульбашев А.Х. Общее учение о личных правах. Москва: Статут, 2019. 255 с.

3. Шайхутдинов Е.М. Эстоппель // СПС КонсультантПлюс. 2021. 
4. Постановление Президиума Высшего Арбитражного Суда РФ от 21.08.2001 № 1194/99; постановление Пленума Высшего Арбитражного Суда РФ от 06.10.2005 № 30 «О некоторых вопросах практики применения Федерального закона «Устав железнодорожного транспорта Российской Федерации»; приложение к информационному письму Президиума Высшего Арбитражного Суда РФ от 22.12.2005 № 96 «Обзор практики рассмотрения арбитражными судами дел о признании и приведении в исполнение решений иностранных судов, об оспаривании решений третейских судов и о выдаче исполнительных листов на принудительное исполнение решений третейских судов».

5. П. 6, "Обзора судебной практики Верховного Суда Российской Федерации N 1 (2017)"(утв. Президиумом Верховного Суда РФ 16.02.2017) (ред. от 26.04.2017). 6. Постановление Пленума Верховного Суда РФ от 22.11.2016 N 54 «О некоторых вопросах применения общих положений Гражданского кодекса Российской Федерации об обязательствах и их исполнении".

7. П. 7 Постановления Пленума Верховного Суда РФ от 23.06.2015 N 25 "О применении судами некоторых положений раздела I части первой Гражданского кодекса Российской Федерации".

8. Постановление Пленума Верховного Суда РФ от 11.06.2020 N 6 "О некоторых вопросах применения положений Гражданского кодекса Российской Федерации о прекращении обязательств".

9. Постановление Пленума Верховного Суда РФ от 24.03.2016 N 7 (ред. от 07.02.2017) "О применении судами некоторых положений Гражданского кодекса Российской Федерации об ответственности за нарушение обязательств". 